DOI: $10.2478 /$ aucft-2013-0012

\title{
EFFECT OF BIOLOGICALLY ACTIVE SUBSTANCES FORMED BY BACCILUS COAGULANS TI ON THE GROWTH OF CROPS
}

\author{
Tatiana LISITSKAYA*1, Tatiana TROSHEVA ${ }^{* *}$ \\ *St.Petersburg State Technological Institute (Technical university) \\ St.-Petersburg, Russia \\ **St.Petersburg State Technological Institute (Technical university)
}

\begin{abstract}
The influence of cultural liquid of bacteria, Bacillus coagulans TI on the growth of several crops are studded. It was established that during the submerged cultivation on glucose-peptone medium these bacteria form gibberellins and amino acids. Pre-sowing treatment of seeds with diluted cultural liquid causes the stimulation of plants growth and improves the quality of plant biomass.
\end{abstract}

Key words: phytohormones, bacteria, protein in plants, structure of a biomass

\section{INTRODUCTION}

Currently, more attention is devoted to microbial interactions with plants, since microorganisms have a significant impact on the development of plants (Akbari et al., 2007), (Karadeniz et al., 2006), (Bottini et al., 2004), (Forni, 1992). Microbial metabolites - growth factors (auxins, gibberellins and cytokinins) - affect not only on the level of crop production, but also on the qualitative characteristics of products, increasing the protein content, essential amino acids and vitamins.

1 Corresponding author. Mailing address: St.Petersburg State Technological Institute (Technical university) Moscowsky, 26, St.-Petersburg, Russia, 190013, lissitskayat@rambler.ru

Vol. XVII (2013), no.2 
According to modern ideas about the regulators of growth and development of plants the phytohormones are substances which are synthesized in plants, transported on them and in small concentrations can cause growth or the formative effects.

It is known that the whole complex of substances that stimulate plant growth synthesize bacteria of the genera Azotobacter, Arthrobacter, Pseudomonas (Tsavkelova et al., 2006). There are cultures of microorganisms that synthesize certain growth factors, for example, Azospirillum brassilence cytokinins (Akbari et al., 2007).

This issue is topical at present because the most important task for present and future of agriculture is to provide the world's population with the high quality products, and to solve this problem a good option might be to obtain bacterial fertilizers. Phytohormones of microbial origin have long been used in crop production, but data on their impact on the quality of plant products is extremely scarce.

\section{MATERIALS AND METHODS}

For the experiments we used the culture of bacteria Bacillus coagulans TI, which was isolated from soil. Bacteria were identified by the complex of morphological, physiological and biochemical attributes by Bergey's Manual of Determinative Bacteriology.

Determination of the concentration of bacteria in the cultural liquids was performed by nephelometric method at a wavelength $540 \mathrm{~nm}$.

Concentration of gibberellins, auxins and amino acids was determined after the precipitation of biomass from the culture liquid. Centrifugation was performed at $6000 \mathrm{rpm}$ for 30 minutes. Methods for determination of gibberellins are based on the color reaction of gibberellic acid with reagent Folin-Chiokalto (Rakitina, 1973). Concentration of auxin in the culture liquid was determined with Salkovsky reagent (Rakitina, 1973). Determining the content of amino acids was performed by the method of Stein - Moore (Lisitskaya, 1996).

The determination of biological activity of cultural liquid was carried out by the tests on the seeds of plants. It is known that the stimulatory action of microorganisms on plant seeds is shown from the moment of their germination. Enrichment of seeds by microbial metabolites was performed by soaking them in the cultural liquid of Bacillus coagulans TI. Duration of cultivation of bacteria was 11 days. For the soaking of the seeds were used cultural liquid, diluted with sterile tap water at $10^{6}$ times. Seeds of wheat, rye, mustard, corn, zucchini, cucumber and radish were placed in sterile Petri dishes and poured a liquid under test. The liquid was poured so that the seeds

Vol. XVII (2013), no.2 
do not suffocate (in an amount of $10 \mathrm{ml}$ ). The experiments were performed in six replicates. As the control sterile water was used. Soaked seed samples were kept at room temperature for 24 hours. During this time the seeds swell by absorbing the products of metabolism of microorganisms from the liquid. The swollen seeds were placed in sterile Petri dishes on sterile filter paper moistened with sterile water. Paper was moistened a certain amount of water - $5 \mathrm{ml}$. In each Petri dish 10 seeds were placed. Germination was continued for 6 days at room temperature. We counted the number of seeds germinated on the first, second and third days. Accounting for germinating seeds allowed to determine their full sprout (FS), community of germination (CG) and speed of germination (SG) for each individual replicates of each variant of the experiment. Full sprout (FS) was determined by the quantity of germinated seeds of this sample.

Community of germination (CG) was calculated as follows:

$\mathrm{CG}=\mathrm{FS} / \mathrm{d}$,

where: FS - full sprout, piece;

$\mathrm{d}$ - number of days of germination, days.

Speed of germination (SG) defined on the sum of average quantity of the seeds sprouting daily. It counted under the following formula:

$\mathrm{SG}=\mathrm{A}+\mathrm{B} / 2+\mathrm{T} / 3$,

where: A - number of the seeds which have sprouted for the first day, piece/day;

B - number of the seeds which have sprouted for the second day, piece/day;

$\mathrm{T}$ - number of the seeds which have sprouted for the third day, piece/day.

After 6 days the sprouts and roots were separated from the seeds and then dried in air at $28^{\circ} \mathrm{C}$ to constant weight. Weights of roots and of green shoots were installed separately. The final result was calculated as the average of six replicates. Comparison of the average weight of roots and green shoots allows to determine the stimulating effect of metabolites of the tested microorganisms.

Micro vegetative experience has been put in three multiple frequencies in plastic vessels in volume of 0,051 filled with a soil. The weight of a soil in a vessel was $85 \mathrm{~g}$. Watering was carried out through the day. Processing of plant seeds was carried out similarly to bioassay. Growth of plants was carried out within 21 days. The protein content in plants was determined by the Kjeldahl method (Lisitskaya, 1996).

Vol. XVII (2013), no.2 


\section{RESULTS AND DISCUSSIONS}

The beginning of the study was the optimization of culture medium for bacteria. The criterion of optimization was selected the concentration of gibberellins in the cultural liquid. It is shown that the qualitative and quantitative composition of phytohormones formed by bacteria depends on many factors: the sources of carbon and nitrogen; the presence of growth factors in the medium. The uses of the nutrient medium components which decrease the biomass concentration cause an increase the production of substances which stimulate the growth of plants by bacteria. The composition of the medium helps to ensure a cultural liquid with a maximum biological activity, g/l: glucose - 10, peptone $-1, \mathrm{KH}_{2} \mathrm{PO}_{4}-0.5, \mathrm{MgSO}_{4}-0.2, \mathrm{~K}_{2} \mathrm{SO}_{4}-$ 0.2 .

To study the dynamics of the formation of phytohormones and biomass accumulation the investigated culture of bacteria Bacillus coagulans TI was grown on glucose-peptone medium in flasks on a shaker $(180 \mathrm{rpm})$. The experiments were conducted at a temperature of $28^{\circ} \mathrm{C}$ within two weeks. The biomass was removed by centrifugation and in the cultural liquid were determined the presence of auxins, gibberellins and amino acids. Results are presented in Figures 1, 2, 3.

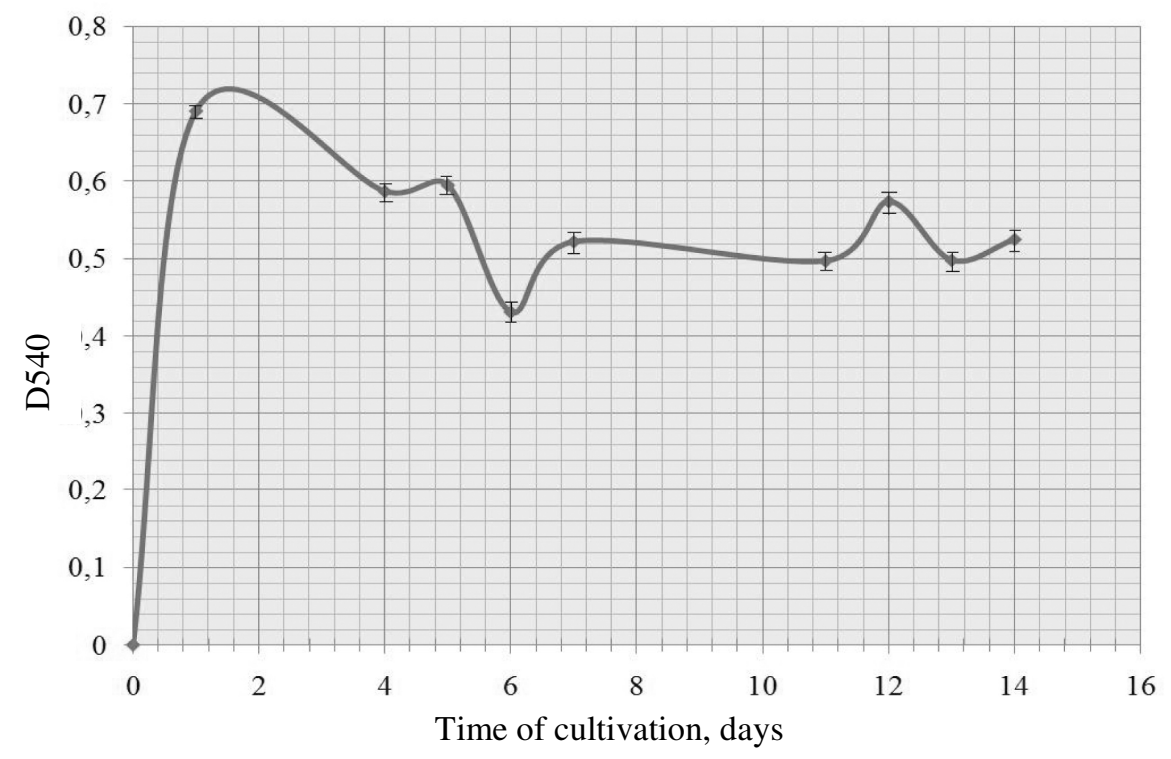

Figure 1. Accumulation of biomass of Bacillus coagulans

As the result of studying the dynamics of bacterial growth and accumulation of phytohormones was revealed that the accumulation of gibberellins in the

Vol. XVII (2013), no.2 
cultural liquids is accompanied by a slowdown in growth of biomass and increase in the content of amino acids. The maximum accumulation of gibberellins falls on the eleventh day and a gradual increase in amino acid content is observed throughout the entire process of cultivation. It was found that the studied culture do not produce auxins.

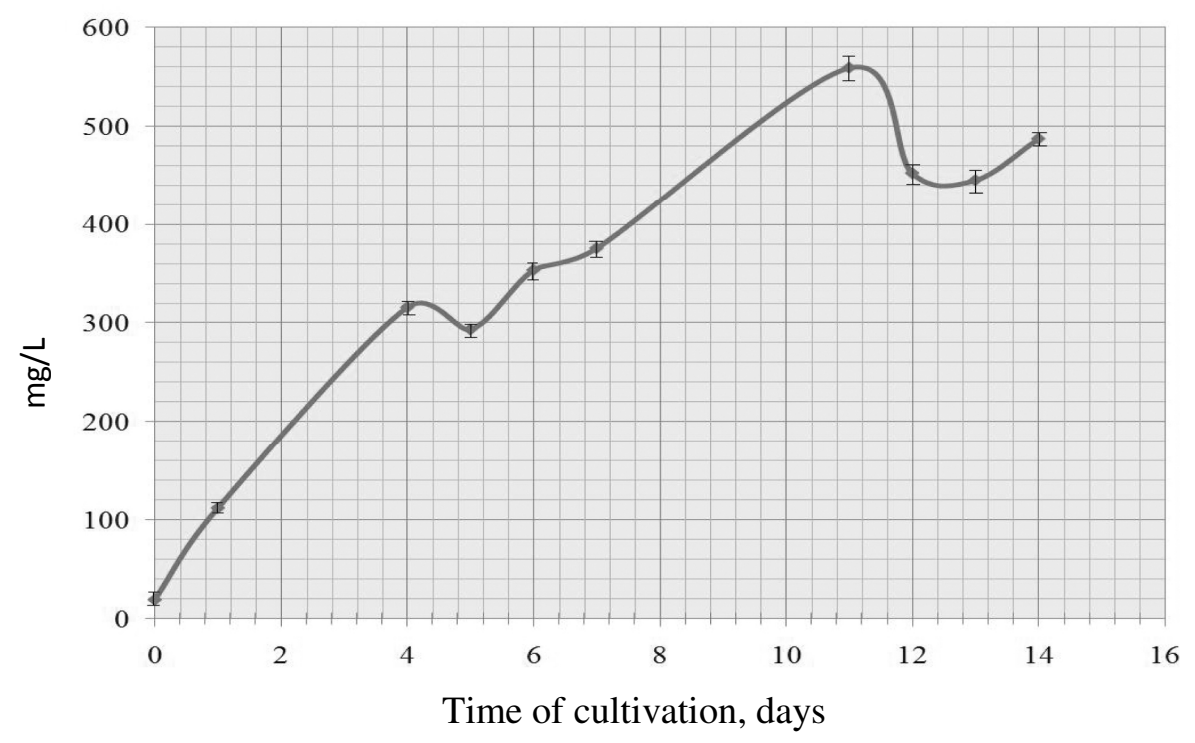

Figure 2. Formation of gibberellins by Bacillus coagulans

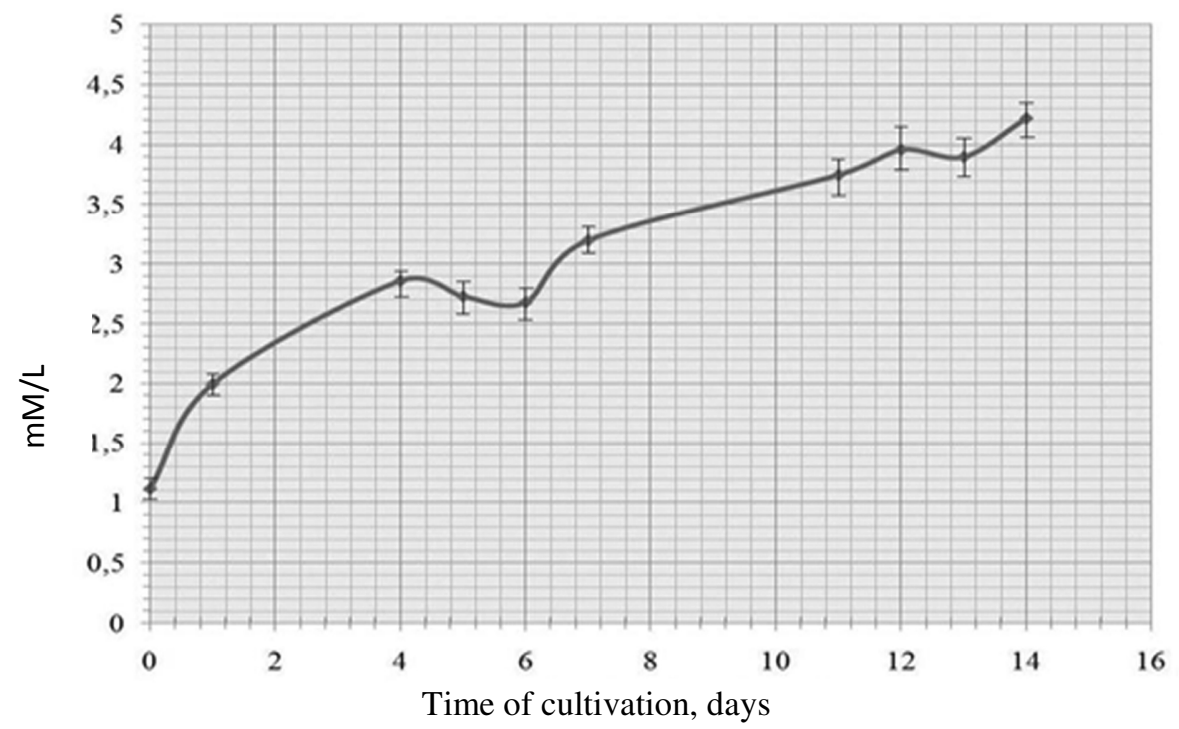

Figure 3. Formation of amino acids by Bacillus coagulans

Acta Universitatis Cibiniensis Series E: FOOD TECHNOLOGY

Vol. XVII (2013), no.2 
The biological activity of cultural liquid was defined by means of the biotest on seeds of peas, wheat, rye, mustard, corn, vegetable marrow and garden radish. The cultural liquid used for processing of seeds was received by cultivation of bacteria on glucose-peptone medium within 11 days. The cultural liquid for soaking seeds was diluted in $10^{6}$ times. As the control the tap water was used for soaking the seeds. Results are presented in Table 1.

Table 1. Influence of processing of seeds by the culture liquid of Bacillus coagulans on sprout, community and speed of germination, $\%$ to the control

\begin{tabular}{|c|c|c|c|}
\hline Seeds of plants & Full sprout (FS) & $\begin{array}{c}\text { Community of } \\
\text { germination (CG) }\end{array}$ & $\begin{array}{c}\text { Speed of } \\
\text { germination (SG) }\end{array}$ \\
\hline Wheat & $111,1 \pm 0,1$ & $106,7 \pm 0,1$ & $111,1 \pm 0,1$ \\
\hline Rye & $101,7 \pm 0,1$ & $101,2 \pm 0,1$ & $113,9 \pm 1,7$ \\
\hline Mustard & $103,5 \pm 0,2$ & $103,1 \pm 0,1$ & $113,5 \pm 1,5$ \\
\hline Corn & $77,7 \pm 3,2$ & $78,0 \pm 3,1$ & $115,2 \pm 1,3$ \\
\hline Garden radish & $107,2 \pm 1,8$ & $107,1 \pm 1,9$ & $109,0 \pm 1,4$ \\
\hline Cucumber & $114,7 \pm 2,4$ & $115,6 \pm 2,6$ & $107,9 \pm 1,2$ \\
\hline $\begin{array}{c}\text { Vegetable } \\
\text { marrow }\end{array}$ & $103,5 \pm 0,4$ & $103,1 \pm 0,3$ & $109,5 \pm 1,3$ \\
\hline
\end{tabular}

From the Table 1 data one can see that the cultural liquid, obtained by submerged cultivation Bacillus coagulans increases the full sprout, community of germination and speed of germination of wheat, radish and cucumber in comparison with control. On the seeds of other plants (rye, mustard, corn and vegetable marrow) the stimulation is noticeable only in the speed of germination. It should be noted that the cultural liquid not only does not increase the sprout and community of germination of corn, but rather the contrary, has an inhibitory effect. The results can be related to the fact that the dilution $\left(10^{6}\right.$ times) is excessive for corn and cultural liquid should be more diluted.

To assess the stimulatory action of metabolic products of Bacillus coagulans TI was also used indicators such as weight of seedlings and roots. The results take into account the weight of seedlings and roots separated from the seeds. A separate weight of green shoots and roots were established. The final result was calculated as the average of six replicates. The results of this experiment are shown in Table 2. Data from Table 2 show that the cultural liquid, obtained by submerged cultivation of Bacillus coagulans greatly stimulates the growth of roots and shoots of mustard compared with control. Strong

Vol. XVII (2013), no.2 
stimulation appears on the seeds of rye and wheat in a weight of roots. On such plants as corn and radishes, metabolic products of Bacillus coagulans have inhibitory effects that may be due to insufficient dilution of the cultural liquid. There is a slight stimulating effect on the dry weight of shoots and roots of vegetable marrow. On the cucumber any effect has been noted.

Table 2. Influence of processing of seeds by the culture liquid of Bacillus coagulans on weight of dry sprouts and roots, $\%$ to the control

\begin{tabular}{|c|c|c|}
\hline Seeds of plants & Weight of sprouts & Weight of roots \\
\hline Wheat & 103 & 117 \\
\hline Rye & 96 & 128 \\
\hline Mustard & 123 & 156 \\
\hline Corn & 21 & 19 \\
\hline Garden radish & 88 & 83 \\
\hline Cucumber & 104 & 105 \\
\hline $\begin{array}{c}\text { Vegetable } \\
\text { marrow }\end{array}$ & 106 & 109 \\
\hline
\end{tabular}

In micro vegetative experiments was shown that after 21 days of growth not only increasing in the length of seedlings of studied plants occurred, but a $10-20 \%$ increase in total nitrogen content in the biomass of wheat, oats and rye was observed.

\section{CONCLUSION}

Thus, the study found that Bacillus coagulans TI belong to the producers of growth stimulating substances (gibberellins, amino acids) and the pretreatment of seeds of a number of agricultural plants with diluted cultural liquid increase the growth and the level of biological value of these plants.

\section{REFERENCES}

1. Akbari, Gh.A., Arab, S.M. et al. (2007). Isolation and Selection of Indigenous Azospirillum spp. and the IAA of Superior Strains Effects on Wheat Roots. World J. Agric. Sci. 3(4): 523-529. ISSN 1817-3047@ IDOSI Publications, 2007

2. Bottini, R., Cassán, F. \& Piccoli,P. (2004). Gibberellin production by bacteria and its involvement in plant growth promotion and yield

Vol. XVII (2013), no.2 
increase. Appl. Microbiol. Biotechnol. 65: 497-503. DOI: 10.1007/s00253-004-1696-1.

3. Forni, C., Riov, J., Grilli, C. \& Tel-Or, E. (1992). Indole-3-acetic acid (IAA) production by Arthrobacter species isolated from Azolla. J. Gen. Microbiol. 138(2): 377-381. DOI: 10.1009/00221287-138-2-377.

4. Karadeniz, A., Topcuoglu S .F. \& Inan, S. (2006). Auxin, gibberellin, cytokinin and abscisic acid production in some bacteria. World $J$. Microbiol. \& Biotechnol. 22: 1061-1064. DOI: 10.1007/s11274-0054561-1.

5. Lisitskaya, T.B., Perstneva, E.A. (1996). Methods of definition of protein and amino acids. St.-Petersburg: St.-Petersburg State Institute of Technology (in Russian).

6. Rakitina J.V. (1973). Methods of definition of phytohormones, growth regulators, defoliants and herbicides. Moscow: Science (in Russian).

7. Tsavkelova, E.A., Klimova, S.Yu., Cherdyntseva, T.A. \& Netrusov, A.I. (2006). Hormones and Hormone-Like Substances of Microorganisms: A Review. Appl. Biochem.Microbiol. 42 (3): 229-235. DOI: 10.1134/S000368380603001X. 